\title{
SOBRE LOS COMICS, LAS HISTORIETAS, LAS PELÍCULAS, LAS NOVELAS Y OTRAS COMIQUITAS IDEOLÓGICAS
}

\author{
Oscar Fernández \\ Universidad Pedagógica Experimental Libertador, Venezuela
}

Resumen.- La ideología vista desde la concepción Marxista nos sugiere que la misma es vista como falsa conciencia y que en consecuencia, todo es sospecho de ser leído como ideología. Ante esta perspectiva no hay otra alternativa que la contra ideología que a su vez puede convertirse en ideología cuando se utiliza como mecanismo de propaganda o como instrumento publicitario caso Los Simpsons. En tal sentido los comics son y han sido instrumentos ideológicos que expresan la intencionalidad de un sistema, en este caso el capitalismo. En otros, socialismo y/o fascismo.

Palabras claves.- Marxismo, ideología, contra ideología, comics

Abstract.- The ideology dresses from the Marxist conception it suggests us that the same one is seen as false conscience and that in consequence, everything is I suspect of being read as ideology. Before this perspective there is no another alternative that her against ideology that in turn can turn into ideology when it is in use as mechanism of propaganda or as advertising instrument I marry The Simpsons. To this respect the comics are and have been ideological instruments that express the premeditation of a system, in this case the capitalism. In others, socialism and / or fascism.

Key words.- Marxism, ideology, against ideology, comics

\begin{abstract}
"Después de Marx, sabemos que el sujeto humano, el ego económico, político y filosófico no es el centro de la historia... Freud, a su vez, nos descubre que el sujeto real, el individúo en su esencia singular, no tiene la figura dé tal ego, centrada sobre el yol la conciencia o la existencia... que el sujeto humano está descentrado. . . "(Louis Althusser: "Freud y Lacan". En Estructuralismo y psicoanálisis, Nueva Visión, Argentina, 1971, página 79)". ${ }^{1}$
\end{abstract}

Habiendo encontrado en la Internet el texto de Ludovico Silva de nombre: LOS "COMICS" Y SU IDEOLOGÍA, VISTOS DEL REVÉS, se me ocurrió que a modo de experimento intelectual y en homenaje al mismo Ludovico, podríamos realizar una especie de diálogo posmorten con él. Que sin pretender burlarnos de Ludovico pudiéramos burlarnos de la oligarquía aniquiladora de la sociedad socialista a través de su ideología. También debemos aclarar que lo que para Ludovico es Comics, para Oscar es algo mucho más amplio que un conjunto de historietas, trasladando semióticamente esta imagen a todos los mass-media, hacemos caricaturas ${ }^{2}$ de los dibujos animados e incluso de algunas series

\footnotetext{
1 Ceiman, Alberto Sladogna. PSICOANÁLISIS Y MARXISMO. Critica al artículo "Apuntes polémicos sobre el psicoanálisis.

2 «La caricatura es un retrato, u otra representación, que exagera los rasgos físicos o faciales, o bien el comportamiento, la vestimenta o los modales característicos de un individuo, con el fin
} 
televisivas que sin ser dibujos sus personajes actúan como tales y más allá aún cuando la vida cotidiana se vuelve y $/ 0$ se confunde con el discurso ideológico/ideologizante/idiotizante, entonces todo es comiquita. Sólo puedo decirles que el diálogo inicial con Ludovico, se transformó en todo un debate con él y otros autores que intentan hacer de esta reflexión un pequeño aporte a la necesidad de aprender a ver con ojo crítico la ideología oculta tras los massmedia.

Pido de ante mano disculpas a los familiares de Ludovico, a los familiares de los demás autores involucrados en este desastre y a los lectores de estas desordenadas ideas que intentan en primer lugar convencer a quien escribe. Veamos como resulta esta locura.

Al referirse Ludovico al mensaje oculto existente en los comics nos dice:

\begin{abstract}
"Su forma ideológica es el "mensaje oculto". Esta expresión la ideó Adorno para la TV, pero es extensible a todos los medios masivos. En el comic norteamericano ésa ha sido casi su forma única, específica, al menos hasta hace poco. Ese mensaje consiste en los supuestos sobre los cuales se desarrolla la historieta." ${ }^{3}$.
\end{abstract}

Ciertamente estamos de acuerdo con Ludovico, no puede ser confiable alguien que como Tarzán ande por allí meneándose de un bejuco y que además como sugiere Ludovico tenga una extraña relación con la mona Chita, todo eso sin hablar de la pobre Jane. Según lo que relata Ludovico sobre Tarzán, este sería algo así como el representante de las nuevas tribus en África o un mormón en cualquier país de Latinoamérica, en otras palabras, Tarzán es de la CIA. La otra versión de George de la Selva se parece más al George Washington, al George Bush (padre e hijo) y pare usted de contar. Por último el Fantasma, me parece que un fantasma que no asusta ya no es un fantasma, y con esa ropa ceñida al cuerpo parece un fantasma travesti. ¿Cuáles serán los mensajes

de producir un efecto grotesco. La caricatura (del italiano caricare, 'cargar', 'exagerar') puede ser también el medio de ridiculizar situaciones e instituciones políticas, sociales o religiosas, y los actos de grupos o clases sociales. En este caso, suele tener un propósito satírico más que humorístico, con el fin de alentar el cambio político o social; su uso queda generalmente restringido a las representaciones gráficas. En América Latina se denomina también caricatura a los cortometrajes de dibujos animados. El cómic o tebeo es una narración contada por medio de una serie de dibujos dispuestos en líneas horizontales y que se leen de izquierda a derecha. Los artistas han desarrollado un vocabulario visual para representar los efectos sonoros; y utilizan símbolos y otros recursos gráficos con objeto de expresar una amplia variedad de elementos narrativos. Estas leyendas aparecen en forma impresa, en publicaciones periódicas específicas, también conocidas en Estados Unidos como cómics, aunque en España se ha popularizado la palabra tebeo, derivada del título de una revista infantil llamada $T B O$, y en algunos otros países de habla española se conocen como historietas. El término cómic deriva de sus orígenes cómicos, pero el humor no es un elemento definitorio, pues el medio se ocupa de asuntos tan variados como pueda hacerlo la literatura o el cine» (Encarta 2000. Caricatura. Cómic).

${ }^{3}$ Silva, Ludovico. Los comics y su ideología vistos del revés:

Escaneo y Revisión: Russo Email: arussoni@yahoo.com

Lista de Discusión: http://groups.yahoo.com/group/el gran hermano/

Blog: http://www.bitacoradelrusso.blogspot.com/

RussoWeb: http://www.geocities.com/arussoni/ 
ocultos detrás de estos disfraces a los que los gringos llaman comics, que habrá oculta detrás del bejuco de Tarzán, la capa de súper man o la sonrisa ${ }^{4}$ de Hello Kitty?

\section{"Así, Superman les habla a los habitantes de un ghetto en rebeldía: "Recuerden que en tanto ciudadanos de los Estados Unidos, ustedes también disponen de un superpoder que no pertenece sino a ustedes: jel voto!" 5}

Debo decir que entre Ludovico y Oscar hay 40 años de distancia. Ludovico escribe sus ideas sobre los Comics en 1971, el mismo año en que nace Oscar. De allí que no sólo halla una distancia espacio/temporal, sino además una distancia experiencial. Él se leyó las historietas, Oscar las vio y sigue viéndolas por la televisión. De todas las historietas que nombra, Oscar, reconoce haber visto en algún momento versiones de: Tarzán, del Fantasma, Astro boy, Súperman, Batman, y de Súper ratón ${ }^{6}$. Sobre Mandraque alguna vez vio una serie que llevaba otro sentido distinto al que Ludovico plantea. Por otro lado es imposible que Ludovico haya visto: Los Simpsons, Mazinger Z, o Ultra man. Por tan solo citar a algunos. A Los Simpsons, dedicaremos una sección al final de este ensayo. Sobre (Mazinger Z y Ultra man) ${ }^{7}$ puedo dar dos breves opiniones. Mazinger $Z$ se trataba de un individuo que llevaba a otro individuo en la cabeza, además ese era el único capaz de manejar al individuo más fuerte es decir; Mazinger. Tal vez la sociedad occidental desde esta perspectiva, necesite a un único individuo especializado que la maneje. Por cierto esa es una de las primeras animaciones venidas desde Japón. Los dibujos parecían más humanos aunque ya comenzaban a distanciarse de los asiáticos. Por supuesto no podía irme sin comentar algo sobre afrodita (la mujer Robot manejada por otra mujer), todavía me vuelve loco la imagen de los senos vueltos proyectiles, será por eso que siempre he buscado mujeres con senos grandes pretendiendo que alguna de ellas me dispare uno algún día.

Sobre Ultra man. Un tipo que luchaba contra monstruos venidos de espacio exterior. Siendo por supuesto él también uno de ellos, siempre aparecía cuando más lo necesitaban y por supuesto al igual que los demás super héroes no tiene vida personal y una ropa ceñida al cuerpo. En mi época estudiantil les decían Ultra man a los hombres que empataban con puras mujeres feas. Claro esto visto siempre dentro del esteriotipo occidental que por supuesto es tremendamente ideológico.

\footnotetext{
${ }^{4}$ Por cierto Hello Kitty no tiene rostro. Es curioso pero este personaje no surgió como los demás, de una historieta o de un dibujo animado que posteriormente derivó en diversos souvenirs, por el contrario primero fueron los souvenirs y luego lo demás. Curiosidades del capitalismo.

5 Idem

${ }^{6}$ Hoy día los super ratones que agarra cada vez que se pasa de tragos son cada vez más frecuentes.

7 Algunos semiólogos interpretan que el trauma causado por las bombas en Hiroshima y Nagasaki, se refleja en aquellas series en las que ellos combaten a uno o varios monstruos y que este monstruo no es otro que el imperio norte americano. Pero cuando se trata de un monstruo que combate monstruos, tal es el caso de Gotzila, entonces los japoneses también se vuelven monstruos sobre todo cuando adoptan el sistema capitalista para destruir a sus enemigos. No faltará quien diga que desde esta perspectiva China también es una Gotzila.
} 
“...ya están apareciendo en Mandrake y El Fantasma, cada vez más insistentemente, ciertos "barbudos" y cierta "isla del Caribe" con características de conspiración infernal. No les queda otro remedio que aceptar la realidad de más de diez años de revolución en Cuba" ${ }^{8}$

Hoy día nadie recuerda a Mandrake pero si a Fidel, la revolución que en Ludovico tenía tan sólo 10 años hoy tiene 50 y sigue...

A mí siempre me resultó sospechoso superman. Un tipo que anda por la calle con los interiores sobre los pantalones es bastante dudoso. Imagino que Ludovico se hubiese horrorizado con los teletubis que sin ser dibujos animados dañaron más que muchos, o con los dibujos japoneses que causaron epilepsia colectiva, o el caso de He $\operatorname{man}^{9}$ los demás súper héroes hipertrofiados que promueven en los jóvenes el narcisismo y el consumo de esteroides anabolizantes, típico de los físico culturistas, que por supuesto se la pasan en un gimnasio. Todos son signos de la degradación de un sistema que nos inoculó la bella durmiente, blanca nieves y los tres cochinitos ${ }^{10}$; entre otras historias como ejemplos modélicos en los cuales los blancos siempre ganan y viven felices para siempre. Desde esa perspectiva no nos disgustaría ser el lobo feroz. Ludovico tal vez nunca se planteo la existencia de una sociedad Coyote, es decir; una sociedad como la gringa en la cual a pesar de su tecnología ${ }^{11}$, el corre caminos del sur América e incluso el de Vietnam, nunca ha sido alcanzado.

Yo confieso profesor Ludovico, que me crié viendo caricaturas de Popeye el marino, si mis padres hubiesen entendido el mensaje oculto, no me habrían comprado espinacas sino marihuana. De eso de verdad. Me arrepiento.

“... la idea de que la raza blanca es la mejor, de que las agencias de inteligencia yanquis están allí para cuidar el orden en el planeta, de que los barbudos de verde oliva son peligrosos, en tanto que es "normal" un individuo como El Fantasma, con overol y traje de baño en plena selva africana; de que, en suma, todo lo que viene de los Estados Unidos incluidas las drogas, el LSD y los marines- es como si viniera del cielo. Del mismo modo, en su inconsciente perdura la imagen del mundo como un gigantesco "arsenal de mercancías", para decirlo como Marx. ¿No es todo esto ideología en estado puro?"12

\footnotetext{
${ }^{8}$ Ibidem

${ }^{9}$ He Man, un super héroe que aunque no lo dijo nunca debió pasar mucho tiempo en el gimnasio. A parte de inyectarse muchos esteroides. Lo que nunca se dijo de los esteroides es que estos producen cáncer, por supuesto me refiero a los esteroides anabólicos, no a los esteroides de otro tipo como los que les prescriben a los artríticos y a los asmáticos, aunque de seguro, esos causarán como todos los medicamentos de la medicina alopática algunos efectos secundarios.

${ }^{10}$ Los tres cochinitos así como la mayoría de los personajes de Disney y de la Warner Brother son seres asexuados. Aquí en Venezuela lo más parecido que tenemos a los tres cochinitos, es el nombre de una manteca de origen animal.

${ }^{11} \mathrm{La}$ industria ACME que siempre le entrega productos increíbles al Coyote. Por cierto alguna vez leí que la industria ACME realmente existe.

${ }^{12}$ Ibidem
} 
Gracias profe. Ludovico ahora entiendo cual ha sido la influencia de la oposición Venezolana. Sin embargo un Jhongo debe haber sido fanático de Batman y Robin (en realidad más de Robin), por eso lo del chico mantequilla. Otros como Leopoldo López de seguro que ha probado LSD y otras cosas con o sin comics. De verdad profe, creo que ahora si estoy entendiendo.

Otros datos camarada, tales como un "Zorro"13 que lucha por la justicia pero no se rebela contra la corona española, ni se plantea un nuevo orden político ni local, ni nacional ni mucho menos global. Un llanero solitario que en su versión original va acompañado de un indio (indígena) al que llama "Tonto", luego la televisión le cambió el nombre a "Toro", que además, pasa 20 veces por la misma piedra, pelea y no se le cae el sombrero y dispara sin recargar. Un Sherlock Holmes que nunca dijo: "Elemental mi querido Watson", Unas caricaturas japonesas que no se parecen a ellos y que por el contrario son blancos, con los ojos grandes y la nariz perfilada. Un James Bond al que nunca se le ensucia ni se le arruga el traje. Unos dibujos animados asexuados tales como: box boni, porki pic, Mike Mouse, etc. Unos super héroes mutantes que según Stan Lee (el creador de Marvel) poseen poderes extraordinarios que sólo pueden enfrentarse contra unos super villanos.

"El personaje central de todas las historietas norteamericanas sigue siendo el mismo personaje central de todo el capitalismo a lo largo de su historia: la mercancía, personaje elemental inscrito dentro de un superpersonaje muy bien representado por especimenes como Superman: el sistema de vida capitalista. Decía también Marx, en el tomo III de El Capital, que en el fondo el capitalismo es una especie de religión de la vida diaria, Religión des Alltagslebens." 14 .

Mcdonals y Rico Mc pato.

\section{El cyborgbiosemiótico}

"Bueno,creo que uno hace la realidad"15. (El robot Bender en Futurama) "Bender no me importa si eres pobre, te amo por tu inteligencia artificial y tu simulador de sinceridad"16 (Condesa Robot en Futurama)

"Si se quiere investigar en biología, psicología o ciencia cognitiva y entender la naturaleza o el pensamiento se intenta computar o simular esas funciones". Y si además "... se quiere incluir una perspectiva histórica o evolucionista, enseguida surgen problemas sobre la cualidad conceptual del signo, la información, el pensamiento y otras categorías

\footnotetext{
${ }^{13}$ Este Zorro se hizo de cómplice a un mudo, alguien que no podía decirle las estupideces que hacía.

14 Ibidem

${ }^{15}$ Groening, Matt. Futurama. Serie televisiva en dibujos animados, transmitida por la cadena FOX.

${ }^{16}$ Idem
} 


\section{importantes"17 (Emmeche, 1991).}

Para entender la dimensión de cómo la semiótica de la vida se ha fusionado al lenguaje de lo cotidiano, tenemos a los cómics quienes desde la visión futurista de seres que por accidente o por nacimiento han adquirido en su mapa cromosómico algunas características sobrenaturales que los convierten en superhéroes, de esta forma la condición de mutante adquiere otra connotación que los transforma en algunos casos en monstruos, y en otros en súper celebridades. Y por supuesto la publicidad oculta detrás de la biotecnología y en particular de la ingeniería genética, es el principal motor de toda esta parodia biotecnosemiótica. Ejemplos hay muchos, y de estos, Stan Lee tiene mucho que decirnos, desde la liga de la justicia, pasando por Los 4 fantásticos hasta llegar a Los hombres " $X$ ", que de alguna forma nos presentan nuevamente la perspectiva de la lucha de clases en la más refinada muestra de la lógica del darwinismo social sino que ahora a través de un marxismo futurista o como tal vez lo diría el mismo Marx: "pos capitalista":

A algunos psicólogos, padres y educadores les preocupaba que las revistas de cómics, en especial las de crímenes y terror, influyeran en la delincuencia juvenil, y ante sus exigencias los propios editores impusieron férreos controles. Muchas de las empresas, debido a ellos, tuvieron que cerrar. Aunque limitados por los códigos de censura y la competencia de la televisión, algunos editores consiguieron revivir en la década de 1960. Un caso destacado fue el de "Marvel Comics, con el guionista Stan Lee, y los dibujantes Jack Kirby y Steve Ditkon, que concibieron un universo interconectado de héroes trágicos como Los 4 fantásticos, Spiderman, Doctor Extraño y Silver Surfer -en español Estela plateada- cuyos poderes sólo les creaban problemas. A partir de entonces, el género de los superhéroes ha dominado la industria del cómic y el estilo impulsado por Marvel se ha impuesto"18. (Enciclopedia Encarta, 2009). Los comics hoy día viven y se expresan a través de diversos medios, así pues los vemos en internet, en películas (ya sea de humanos o de dibujos animados), en videos, en presentaciones en power point, en medios impresos, en juguetes, a aparte de todo esto y tomando en cuenta las características de algunas personalidades públicas (noveladas o no), son también incluibles dentro de la categoría caricaturesca de comics.

Este enfoque de los superhéroes, nos viene de Estados Unidos, país este que de alguna forma a través de su psiquis colectiva, pretende ofrecer/vender al mundo su esquema mental de seres sobrenaturales y por ende superiores; por ello volvemos a Los hombres " $X$ " o "X men", que presenta de forma subjetiva, la clásica lucha de clases y además la frustración que representa para los supuestos seres superiores, el no poder vivir una vida normal, tal es el caso del personaje de nombre "Titania" que pese a poseer el poder de quitarle el poder y energía a los demás, no puede siquiera enamorarse, pues un beso de ella significaría la muerte para quien lo haga excepto para Logan, (Guepardo o Wolverine) quien posee un tremendo poder regenerativo. Volviendo a la comparación con Estados Unidos de América, debemos

\footnotetext{
17 Grupo de estudios Biosemióticos. Dinamarca. http://home.comcast.net/ sharov/biosem/

${ }^{18}$ Microsoft. Encarta. 2009.
} 
recordar que en estos momentos ha sido esa nación a través de su ambición capitalista la que ha generado una de las mayores crisis en la historia del mundo capitalista, y que por consecuencia ha hecho de los problemas y complejos de una cultura, la crisis de un mundo que no tiene en mucho nada que ver con todo esto, más que el haber sido tremendamente pasivos ante el poderío bélico de los súper héroes del norte.

El único héroe que no han creado ha sido: "Súper Paz", un héroe que en la lógica de los citados arriba sería tal vez un anti héroe, creo que debemos comenzar a observar con detalle a los "villanos", para ver qué tan villanos son, e intentar soñar con un correcaminos, que es alcanzado por el coyote algún día, y que como lo hemos visto va decididamente por el camino equivocado. Aunque si lo vemos por otro lado y si de encontrar culpables en todo esto, creo que la culpa es de la empresa $A C M E$, que a mi modo de ver no sólo representa al imperio capitalista positivista, sino que además nos muestra el como sus supertecnologías no son suficientes para alcanzar sus objetivos de desarrollo y felicidad. Esa adoración a la ciencia y a la tecnología que nos presenta a un ser salvado a través de los poderes todopoderosos de la tecno-magia, y que de alguna forma nos ha atrapado en el caos cuántico de lo real y de lo virtual haciendo no en pocos casos de la metafísica una metatécnica, que nos transmite desde nuestros sistemas de creencias la posibilidad de transformar el mundo y a la vez ser salvado del Armagedón, de esta forma los físicos cuánticos se han convertido en los supremos sacerdotes de este nuevo estado espiritual.

Sobre Mandrake el Mago Ludovico nos dice:

"En su propia casa tiene teléfonos especiales que lo comunican, cada vez que se presenta algún problema, con una misteriosa oficina situada en los subterráneos de una lavandería; oficina que, o mucho nos equivocamos, o es la Agencia Central de Inteligencia, que también tiene contrato de trabajo con El Fantasma, Superman, Ben Bolt, Rip Kirby y una serie más de agentes "no oficiales", cuya misión específica es hacer "como si trabajaran por su cuenta". "19.

Aquí tenemos a otros agentes de la CIA, tales como: los testigos de Jehová, los Mormones, algunos adecos, María Corina Machado; entre otras especies en vías de extinción.

\footnotetext{
${ }^{19}$ Silva, Ludovico. Los comics y su ideología vistos del revés:

Escaneo y Revisión: Russo

Email: arussoni@yahoo.com

Lista de Discusión:

http://groups.yahoo.com/group/el gran_hermano/

Blog:

http://www.bitacoradelrusso.blogspot.com/

RussoWeb:

http://www.geocities.com/arussoni/
} 
Volviendo a los super héroes, si existe liga de la justicia, existe también legión del mal, lo curioso es que todos viven en Nueva York. Algo así como la OEA y la ONU. Otra cosa curiosa es que no sabemos si estos super héroes reciben algún salario y quien les paga. Con excepción del capitán América es muy es un poco dudosa el origen de algún estipendio al respecto. Sobre la naturaleza étnica de los super héroes, ocurre casi que lo mismo que con los científicos, es decir; tienen casi todas las nacionalidades de origen pero todos, poseen el pasaporte gringo. De allí podemos deducir quien les paga. Ahora bien debemos tener claro que no sólo les pagan los de la liga de la justicia sino además a los de la legión del mal.

Sobre los dibujos animados dramáticos: ejemplos de estos son: Heidi, Candy Candy y Marco 20 .

Sobre Heidi podríamos decir es una niña poco normal, ya que una persona que le pregunta a su abuelo: Abuelito dime tú, ¿Qué sonidos son los que oigo yo? Abuelito dime tú, ¿Por qué yo en una nube voy?, ¿Dime porque huele el aire así?, ¿dime porque soy tan feliz?, obviamente está bajo el efecto de algún alucinógeno. De allí que el humorista Colombiano Andrés López dice que Heidi es drogadicta. Yo particularmente me inclino más por la tesis de la esquizofrenia. En cualquier caso podre abuelito. Por otro lado tenemos a Pedro. Esperando eternamente a ver si le dan algo de sexo, cosa que nunca se ve a menos que ocurra en comerciales.

Con Candy Candy es prácticamente lo mismo, una chica disfuncional, que no sabe si estar con Anthony o con Terri. Pero además si le sumamos a esto el doblaje Argentino que nos enviaron, le imprime un drama con sabor a tango. Me gustaría verla versión Gocho. Creo que Candy Candy fue una de las primeras animaciones que nos enviaron los japoneses, ya allí comenzábamos a ver los ojos grandes y las narices de quirófano.

De Marco no puedo decir gran cosa, porque a esa hora estaba haciendo algo más importante. Estaba jugando. Sólo sé que es un niño italiano de la época de la posguerra que va a buscar a su mamá a la argentina. No recuerdo si al final la encuentra. Como ya dije estaba haciendo algo más importante. Mi mamá estaba en mi casa.

Otra serie televisiva que marcó época para mi generación fue: Meteoro. Otro personaje disfuncional que tenía una novia que volaba helicópteros y a la que el héroe tampoco le hacía nada. Con un padre gritón, una mamá que casi no

${ }^{20}$ conocida como Tres mil leguas en busca de mamá, o también como De los Apeninos a los Andes, es una serie de anime basada en el relato Marco, de los Apeninos a los Andes incluido en la novela italiana Corazón de Edmondo de Amicis. La serie fue emitida originalmente en Japón en el año 1976, parte del contenedor infantil World Masterpiece Theater o Meisaku de Nippon Animation. El contenedor había antes y después producido una gran variedad de series de animación basadas en diferentes obras literarias infantiles; entre ellas estaban El perro de Flandes (1975) y Rascal, el mapache (1977). En España, la serie fue emitida a través de varios canales como Televisión Española, Antena 3 y Tele5; también en España, la serie está disponible en una serie de DVD distribuida por Planeta Junior.

http://es.wikipedia.org/wiki/Marco_(anime) 
sale en la serie, un hermano menor que siempre se cola en la maleta del vehículo junto con su mascota un chimpancé. Al igual que en Tarzán, siempre quedará la duda sobre la relación de chispita con chito. A parte de esa fijación por meterse en la maleta. A parte de todo esto Meteoro tiene un hermano que desapareció (Rex) y al que creen muerto y que al final siempre lo salva, este es el enmascarado " $X$ ". Este enmascarado termina siendo un agente de la CIA. Por supuesto falta nombrar a la estrella del programa que a diferencia de lo que todos creen no es Meteoro es el auto al que llaman Mach 5. Este carro hace de todo menos hablar. (Claro el que habla es el auto fantástico, otra serie) en meteoro todo se traduce en aventuras a través de carreras de carros en la cual por supuesto siempre gana Meteoro, en algunas ocasiones con la ayuda de su hermano misterioso. Aquí sólo podríamos destacar la idolatría a la tecnología la cual es una constante en casi todos los dibujos animados.

Así como Ludovico habla en su artículo de Lorenzo y Pepita, refiriéndose a la típica familia clase media alienada del y por el capitalismo. También tenemos el caso de los Picapiedras y los supersónicos, los cuales ubicándose unos en la edad de piedra y otros en el futuro lejano, nos hablan de un par de familias felices con su condición de explotados y asalariados y que además les deben su felicidad a la tecnología.

Entiendo que Ludovico señalara sólo los comics de su época los cuales se veían más que todo, a través de historietas. Ahora con la televisión por cable y/o satelital, el cine y la internet. No se me hace fácil el trabajo. Sin embargo lo estoy intentando. Confieso además que no llevo un orden cronológico en la aparición de los elementos de análisis, van apareciendo en la medida en que me voy acordando de ellos.

Si analizamos por ejemplo el caso de la gata loca e Ignacio. Ella es evidentemente es masoquista y el es un sádico. Pero más allá de eso ella es una gata y él un ratón. Si lo llevamos a personas podrían ser personas de clases sociales muy diferentes o de diferentes grupos étnicos que por supuesto también llevan implícito las clases sociales. Pero si giramos el ojo y notamos que los gatos por naturaleza se comen a los ratones y esta gata está enamorada de su comida que por demás la lastima tal vez estemos viendo entonces a una sociedad anoréxica, bulímica o tremendamente obesa como la norte americana.

Por otro lado tenemos el caso de los padrinos mágicos. Unos padrinos que sólo aparecen si tienes una niñera mala, es decir di esta desaparece incluso con la magia de los padrinos, estos también desaparecen. $Y$ por otro lado puedes tener todo lo que quieras pero sin faltar a las reglas. A esas reglas en nuestra sociedad las podríamos llamar leyes las cuales como ya sabemos siempre favorecen los intereses de la burguesía. Ludovico dice lo siguiente refiriéndose a Mandraque al final creo que el análisis es el mismo:

“... Frente a la "cosificación de las personas y la personalización de las cosas" (Marx), ¿qué hay de maravilloso en hacer creer a un chino comunista que se lo tragará un inmenso dragón? ¿Y qué hay de maravilloso en este mismo dragón si lo comparamos con su capacidad de 
representar ocultamente la presunta vigencia del "espíritu" feudal prerrevolucionario?"21.

Yo por mi parte para contrastar un poco la visión de Ludovico voy a colocar algunas citas de Isaac Asimov en su novela de ciencia ficción Fundación y tierra y al igual que Ludovico lo analizaremos:

“¡Sí! - exclamó Trevize -. ¡Exacto! Escogí Gaia, un superorganismo; todo un planeta con una mente y una personalidad comunes, de manera que hay que decir "yo-nosotros- Gaia» como un pronombre inventado para expresar lo inexpresable. - Empezó a pasear con nerviosismo de un lado a otro -. Y, en definitiva, se convertirá en Galaxia, un supersuperorganismo que abarcará todo el enjambre de la Vía Láctea"22.

"Pero, ¿por qué no te gusta o desconfías de tu decisión? Trevize respiró hondo y dijo lentamente, en voz grave y forzada:

- Porque no quiero formar parte de un superorganismo. No deseo ser una parte prescindible que pueda ser arrojada por la borda cuando el superorganismo considere que eso puede redundar en beneficio del todo"23.

Al igual que como analiza Ludovico, observamos que muchos miles de años en el futuro parece que aún sigue el imperialismo. Pero a diferencia del caso Mandraque aquí surge una bifurcación. El imperio galáctico fracasó y existe la posibilidad de que se establezca galaxia otra organización en la cual al parecer se pierde la individualidad y prevalece el colectivismo. Sin embargo Trevize no está seguro de querer formar parte de galaxia pues teme perder su individualidad. De este modo tenemos dos posturas profundamente antagónicas, por un lado imperio que es el reflejo galáctico de la expresión común: "Juntos pero no revueltos", por otro lado tenemos a un super organismo que niega la individualidad hasta para ir al baño. Nos encontramos pues ante el futuro de la humanidad vislumbrada por un escritor de origen soviético que creció en Nueva Cork y que vivió en la época de la guerra fría.

¿No pasaría lo mismo con la llegada del socialismo? ¿Toda la humanidad estaría dispuesta a colectivizarse y a perder su individualidad? ¿No serían más convenientes posturas intermedias? Por supuesto que estas son posturas radicales que al final no conducen a nada. Sin embargo no pocos disque revolucionarios juegan a lo colectivo es decir: hablan siempre en plural, escribe en conjunto y no colocan autoría a sus textos y todo lo deciden en asambleas. ¿No será eso una suerte de religión de lo colectivo? Al fin y al cabo ¿que pasaría si todos pensáramos igual? Por otro lado si la dialéctica se traduce en un movimiento permanente, entonces la llegada al socialismo se traduciría en la búsqueda hacia otro nivel superior y así sucesivamente por siempre. Estableciendo un perpetuo ir y venir dialéctico/dialógico que pondrá siempre a

\footnotetext{
${ }^{21}$ Idem

${ }^{22}$ Asimov, Isaac. Fundación y tierra. Descargado de eBooket: www.eBooket.com

${ }^{23}$ Idem
} 
flote las profundas contradicciones humanas que por demás nunca se detendrán.

\section{LA OTRA HISTORIA DETRÁS DE LAS HISTORIETAS}

Según declaraciones dadas por diversos hacedores de historietas en los estados unidos y transmitido a través de un programa en History Channel de nombre: Súper héroes detrás de las máscaras, las historietas de súper héroes vivieron tres epatas:

En los años 30 (época de la gran depresión), eran vistos como rebeldes y justicieros.

En los años 40 (época de la segunda guerra mundial) eran patriotas y en los años 50 eran una amenaza para el senado de los estados unidos (tal eran más una amenaza para la creciente industria televisiva). En la segunda guerra mundial las ventas de historietas aumentaron tremendamente y además se les enviaban a los soldados en combate. Qué curioso en las historietas los norte americanos siempre ganaban. Una cuestión irónica es que ellos combatían contra los Nazis y las acciones de los personajes de las historietas defensores de la justicia, eran más fascistas que los mismos Nazis.

Súper man que cada vez más se convertía en un funcionario del orden establecido se hacía notar con la siguiente consigna:

\section{"LA VERDAD LA JUSTICIA Y NUESTRA FORMA DE VIDA"}

A los creadores del mismo súper héroe de origen judío de apellidos Siegel $^{24}$ y Shuster ${ }^{25}$, respectivamente, los usaron y hasta les habían robado la autoría, cosa que al final recuperaron parcialmente pues la empresa editora siempre conservó los derechos aún voracidad del capitalismo. En 1948 un siquiatra de origen alemán de nombre Fredric Wertham ${ }^{26}$, fue el principal testigo en contra de las historietas en una interpelación hecha por el senado de los estados unidos, el mismo publicó en un libro de nombre: "La seducción del inocente", decía cosas tales como que: Batman y Robin representaban a una pareja de

24 Jerome "Jerry" Siegel (October 17, 1914 - January 28, 1996 ${ }^{[1]}$ ), who also used pseudonyms including Joe Carter, ${ }^{[2]}$ Jerry Ess, ${ }^{[2]}$ and Herbert S. Fine, was the American cocreator of Superman (along with Joe Shuster), the first of the great comic book superheroes and one of the most recognizable of the 20th century. He was inducted (with Shuster posthumously) into the comic book industry's Will Eisner Comic Book Hall of Fame in 1992 and the Jack Kirby Hall of Fame in 1993. http://en.wikipedia.org/wiki/Jerry_Siegel

25 Joseph "Joe" Shuster (Toronto, 10 de julio de 1914 - Los Ángeles, 30 de julio de 1992) fue un dibujante de cómics estadounidense nacido en Canadá, creador, junto con Jerry Siegel, del célebre personaje de la editorial DC Comics Superman, aparecido en el primer número de la revista Action Comics en marzo de 1938. http://es.wikipedia.org/wiki/Joe_Shuster

${ }^{26}$ Fredric Wertham (20 de marzo de 1895 - 18 de noviembre de 1981), psiquiatra germanoestadounidense protagonista de una cruzada para protestar contra los supuestos efectos nocivos de los medios de comunicación de masas - los cómics, en particular- en el desarrollo de los niños. Su libro más conocido fue La seducción de los inocentes (1954), que condujo a una comisión de investigación del Congreso de los EE. UU. contra la industria de los comics y a la creación del Código del cómic. http://es.wikipedia.org/wiki/Fredric_Wertham 
homosexuales que viven juntos, llegó a hablar del complejo de súper man, que se refería al goce sádico que produce dañar a otros y permanecer inmune, y la mujer maravilla era lo contrario de lo que las mujeres deben ser.

Otra cuestión curiosa es el hecho de la creación de la mujer maravilla. Su creador fue el sicólogo de Harvard Williams Mouton Marston ${ }^{27}$, quien a su vez contribuyó en la creación del detector de mentiras. Cabe destacar que dicho autor convivía en la misma casa con su esposa y con una ex alumna con las cuales tenía hijos.

En los años sesenta, época en la que las protestas y los movimientos pacifistas proliferaron en los estados unidos, un colectivo de estudiantes supuestamente progresistas, colocaron entre sus iconos a: Hulk, y el hombre araña junto a Bob Dilan, Malcon X y el Che Guevara. ¿Qué tal? En los años 60 que a mi parecer fue el momento más cercano a una posible reacción hacia la búsqueda del socialismo en dicho país, vemos como las historietas jugaron un papel en la trivialización de dicho proceso emergente que al parecer no pasó del ámbito académico.

\section{SOBRE LOS SIMPSONS}

Sobre la serie anima Los Simpsons podría decirse mucho, tan es así que Juan Pablo Marín Correa, le dedica todo un libro el cual lleva por nombre: Detrás de los Simpsons

Comunicación - Sociedad - Cultura. Sin embargo el mismo autor no pudo escapar a su naturaleza capitalista, siendo el mismo publicista y por tanto sólo se puede obtener el libro si lo compras, apenas pude obtener la presentación e introducción del mismo. Por ello procederemos a realizar nuestro propio análisis no sin antes indicar que el mismo es tremendamente parcial ya que después de 21 temporadas y corriendo la 22, a pesar de ser seguidor de la serie, el hecho de no tener las grabaciones a la mano, se convierte en un elemento limitante de la misma.

Lo primero que debo decir, es que su creador Matt Groening, sea cual sea su tendencia política, es un verdadero genio, al poder retratar a la sociedad norte americana e incluso a la nuestra. Y por otro lado debo decir que él ha podido hacer de la contra ideología, una ideología. Ahora: ¿Como un canal como la FOX, tan tremendamente defensor del status quo de la sociedad norte americana, puede transmitir un programa tan crítico como los Simpsons?, la única respuesta lógica que hasta ahora he encontrado es que los televidentes de izquierda también son un target, es decir un segmento al que el mercadeo debe cubrir y dirigir sus productos. En este caso una serie que ofrece críticas socioculturales. Por otro lado esta imagen de falsa

${ }^{27}$ El Doctor William Moulton Marston (9 de mayo de 1893 - 2 de mayo de 1947) fue un psicólogo, feminista, teorista, inventor, y autor de historietas que creó al personaje de la Mujer Maravilla.

http://es.wikipedia.org/wiki/William_Moulton_Marston 
tolerancia los hace ver ante al mundo como una sociedad abierta y comprensiva. Sin embargo todo sabemos lo poco tolerantes que los gringos han sido por ejemplo con los 5 Cubanos presos, o con las personas indefensas de Irank y Afganistán.

Recientemente observé un programa en el que a Bart un burro que habían llevado para un concurso ridículo de básquet en burro, le come los pantalones cortos y éste queda con el ponéis señalando a la bandera. A partir de allí comienza una campaña en contra de Bart, en la que lo acusan hasta de comunista.

En otra a Homero se le dañan sus pantalones azules, este comienza una campaña publicitaria que lo lleva a la reelaboración de dicho producto que había quedado descontinuado. Al final del programa, Homero sigue haciendo publicidad a través de mensajes escritos en su cuerpo. Uno de ellos dice: "Reelijan a Chávez".

En otro episodio, un grupo de genios entre los cuales se halla Lisa, deciden dirigir el pueblo y este se vuelve un caos que sólo lo calma Stephen Hawking, según ellos el hombre más inteligente del mundo. El cual cierra el episodio diciéndole a Homero que le va a robar su teoría del "Universo visto como una rosquilla".

En otro episodio a Lisa la llaman para formar parte de la sociedad secreta MENSA. La cual reúne a las personas con los IQ más altos de la historia. Irónicamente el término mensa indica en el argot Mejicano a una mujer tonta.

En un artículo publicado por Claudio Horacio Sánchez, en la revista Números. Revista de didáctica de las matemáticas, publicó un artículo de nombre: Los diez mejores momentos matemáticos de Los Simpson. He aquí 2 fragmentos de lo que Claudio publicó:

\section{2 - Para, o mi perro dispara}

Este es el episodio en que el perro de Los Simpson ingresa a la academia de policía. Al comienzo del capítulo la familia se pierde en un laberinto de maíz del que logran salir gracias a Lisa que dice "les dije que podríamos salir aplicando el algoritmo de Tremaux". Efectivamente, este algoritmo es un método para salir de laberintos y fue desarrollado por un ingeniero francés de apellido Tremaux. Consiste, básicamente, en marcar cada camino que se toma y no tomar el mismo camino más de dos veces. El método garantiza que recorreremos todo el laberinto y, tarde o temprano encontraremos la salida. Si el laberinto no tiene salida, regresaremos al punto de entrada. El algoritmo de Tremaux se parece bastante al que trata de aplicar el protagonista de El nombre de la rosa cuando se pierde entre las salas de la biblioteca de la abadía: él también habla de hacer marcas sobre los caminos. Sin embargo, el algoritmo de Tremaux fue enunciado en 1832, mientras que la novela de Umberto Eco transcurre en el siglo XIV. 


\section{0 - Edna especial}

La maestra Krabbappel es nominada al premio de Maestra del año. Al final pierde el premio a manos de "Julio Estudiante, por haber enseñado a los estudiantes que las ecuaciones diferenciales son más poderosas que las balas". Este "Julio Estudiante" alude a Jaime Escalante, un profesor de matemáticas boliviano que enseñaba en una escuela de los barrios bajos de Los Ángeles y que logró que sus alumnos destacaran en matemáticas compitiendo con estudiantes de las mejores escuelas del país. La historia de Jaime Escalante se cuenta en la película Con ganas de triunfar, (título original: Stand and deliver, literalmente "póngase de pie y diga la lección"), filmada en 1984, con Edward James Olmos en el papel principal."i28.

Como vemos los Simpsons, si es una serie cargada de mucha ideología, tanta que se confunde a veces con contra ideología. Pero no es cualquier ideología. $Y$ no es precisamente la ideología que el camarada Ludovico vio aunque si la advirtió.

Es obvio que los Físicos y Matemáticos que son guionistas de Los Simpsons, son tremendamente ideologizados por el sistema capitalista que representan. Pero no menos que los científicos nuestros que creen que sólo pueden hacer ciencia si y sólo si trabajan en un instituto de investigaciones o en una Universidad, publicando además sus trabajos para la NASA.

\section{SOCIOPATOLOGÍA DE ALGUNOS DE LOS PERSONAJES DE LOS SIMPSONS}

Comienzo diciendo que el nombre de sociopatología y no sicopatología reporta o pretende reportar, un conjunto de patologías sicológicas que de una u otra forma son signos de patologías sociales propias de una sociedad norte americana en decadencia, que por supuesto no deja de afectar a la nuestra.

Recordemos que de los comics que han reflejado mejor la sociedad norte americana, tenemos el caso de los Picapiedra y los Supersónicos, los cuales son si se quiere el marco referencial de los Simpsoms. Recuerdo que en una oportunidad, la esposa de Sónico (ultra), se enfermó por que se le inflamó un dedo. Y por supuesto había un médico especialista en dedos. Es obvio que desde ese momento y antes inclusive ya nos vendían la idea de que la tecnología sería la solución a todos nuestros problemas y por consecuencia sólo nos enfermaríamos del dedo por presionar tantos botones en el día. Otro ejemplo también venido de los años 60 y 70 . Es el caso de la serie viaje a las estrellas. (y me refiero a la serie original con el Capitán Kirk y el Sr. Spock), en

28 Sánchez, Claudio Horacio. Los diez mejores momentos matemáticos de Los Simpson. Revista Números de didáctica de las matemáticas. Marzo 2010.Volumen 73. http://www.sinewton.org/numeros Volumen 73, marzo de 2010, páginas 3-4 ISSN: 1887-1984 
una oportunidad el Dr. Macoy (el médico de la nave) viaja al pasado es decir; al siglo XX, allí van a un hospital, y en el mismo hay muchas emergencias, se tropieza con un herído que tiene problemas en un riñón, el Dr. Macoy lo examina con un aparato y le da una pastilla. Inmediatamente se oye un grito... le creció un riñón. Es evidente que la fe en la ciencia en esa época era tremenda. Hoy día sabemos que si nos dan una medicina para curar algo, de seguro nos enfermaremos de otra cosa, ya que la visión de la medicina no es sistémica sino reduccionista y fragmentaria. Ahora sí comenzaremos a hablar de los Simpsons propiamente:

Marge: Hemos visto a Marge, neurótica producto del infierno sicótico que vive con su familia, la hemos visto alcohólica y ludópata, inmersa en un mar de insatisfacciones y obligada a vivir una vida incompleta. A pesar de todo esto se le ocurren grandes empresas que logra desarrollar hábilmente y que luego desaparecen para ser nuevamente la misma Marge de cada episodio.

Homero: Un personaje tremendamente controversial, lo hemos visto drogarse con marihuana, e incluso decir que necesita anti-sicóticos, ha practicado todos los oficios que se les han ocurrido a los guionistas, más sin embargo al final de cada episodio siempre vuelve a la planta nuclear, el sitio que más detesta pero al que se ve obligado a asistir.

Bart: El típico niño hiperactivo que usualmente es estigmatizado como un niño malo o niño problema, es tremendamente creativo a la hora de hacer alguna travesura y detesta a la escuela al igual que su padre el trabajo. Bart también visita al siquiatra y también consume drogas.

Lisa: La típica niña genio que aspira ir a Harvard, ella es uno de los mejores reflejos de su propio sistema. En una ocasión cerraron por un tiempo la escuela y ella se puso neurótica porque como cualquier adicto necesitaba su dosis diaria de escuela y de calificaciones excelentes. Este episodio llega a su punto cumbre cuando ella se acerca al cuarto de sus padres y les lleva un aparato de movimiento perpetuo, Homero cierra el instante gritándolo: "Lisa en esta casa respetamos las leyes de la termodinámica". Ella sueña con ser la presidenta de los Estados Unidos. Por supuesto Bart según los estereotipos terminará siendo un vago. Lisa siendo tan supuestamente inteligente nunca cuestiona a la ciencia y a la tecnología de su país. Lisa es en consecuencia la anti-Mafalda. Además de todo esto Lisa nos advierte sobre la ideología oculta detrás de los estereotipos, ya que Lisa es Vegetariana, ecologista, feminista, pacifista, budista, academicista y sobre todo sueña con ser la presidenta de los estados unidos. En consecuencia una Lisa pone en duda la práctica de mucha gente de izquierda en el mundo ya que sino algunos por lo menos uno de estos estereotipos, los hemos adoptado como forma de lucha. Vemos aquí como el capitalismo puede mofarse de nuestro discurso e incluso hacerlo suyo con casos como el de Al Gore (premio Nobel de la paz y premio de la academia de ciencias y artes cinematográficas), Obama (premio Nobel de la Paz), por tan sólo citar los más recientes.

Montgomery Burns: El señor Burns no sólo es el dueño de la planta nuclear, sino que además es él, la representación misma del capitalismo. Lo interesante 
en esto aparte de presentarnos a un a anciano económicamente poderoso, nos muestra a la vez a un hombre físicamente imposibilitado.

Maggi: Esta bebé también es adicta a los chupones nunca habla y nunca crece. Un mensaje bien interesante para el pensamiento norte americano, el cual como Maggi nunca habla y nunca crece.

Moe: Es un depresivo suicida acomplejado.

Karl y Leni: No sólo son Homosexuales interraciales sino que además sus nombres curiosamente se asemejan a los de Karl Marx y Lenin.

Krosty el Payaso: también es drogadicto, es agresivo excepto cuando está al aire en su programa y mantiene un constante conflicto con su origen Judío. Es además el dueño del Mcdonals de la serie, y como si fuera poco es el presentador de la serie animada Tomi y Daly, una versión morbosa de Tom y Jerry, en la cual Daly siempre termina con Tomi de una forma sangrienta.

Mr. Smiders: Un homosexual adulador enamorado del Sr. Burns.

Ned Flanders: Un fanático religioso que ni el Reverendo Alegría tolera. Ned no sólo es la expresión del aparato ideológico de estado religioso en términos de Althusser, sino que además representa la adoración a un sistema que nunca cuestiona. Ni siquiera cuando se percata de la marcada formación homosexual de sus hijos.

Otto: El conductor del autobús de la escuela es un drogadicto, que alucina al conducir y que se siente muy atraído por los colores llamativos.

En relación a la decadencia que significan los Simpsons, Fernando Buen Abad Domínguez nos dice:

"Los Simpson son, además de sus virtudes mercantiles y su capacidad de seducción, apología de la resignación en casa. Marketing de la mansedumbre que, en lugar de transformar al mundo capitalista propone una autoridiculización tan estéril como peligrosa para permitir que un grupo empresarial de la farándula en plena guerra mediática gane mucho dinero. Parodia grotesca en tono triunfador para que la mediocridad se legitime como identidad de la clase explotada. Y los tenemos en casa. ¿Ya nos dimos cuenta?" 29

Vuelvo nuevamente con lo que dije arriba, es decir: Con los Simpsons han logrado hacer de la contra ideología una ideología, al hacer la sátira del sistema decadente norte americano, que tal vez nosotros debimos haber hecho. Claro tal vez de otra forma o con otro estilo. Tal deberíamos volver al "Mago de la cara de vidrio de Eduardo Liendo", por ejemplo. Debemos dar la batalla y no dejar que ellos nos digan que es y que no es bueno, porque desde allí nos aniquilarán y de paso ganarán mucho dinero con ello.

29 Abad Dominguez, Fernandeo. La irreverencia marcantilizadora y la decadencia como entretenimiento. Los Simpsons. http://www.rebelion.org/noticia. php?id=66305 
Una de las hermanas de Marge, es lesbiana al abuela nadie le hace caso, jefe de policía Gorgory es estúpido y además es de origen irlandés, Apu es de la india y es el encargado del mini mercado, hay el dueño de una pizzería que no sé cómo se llama. Etc.

Estos son sólo algunos de los personajes pero creo que desde aquí podemos hacernos una idea de lo enferma que está la sociedad norteamericana, para comprender mejor esto colocaremos una cita de Desmond Morris:

"En condiciones normales, en sus habitats naturales, los animales salvajes no se mutilan a sí mismos, no se masturban, atacan a su prole, desarrollan úlceras de estómago, se hacen fetichistas, padecen obesidad, forman parejas homosexuales, ni cometen asesinatos. Todas estas cosas ocurren, no hace falta decirlo, entre los habitantes de las ciudades. ¿Revela, pues, esto, una diferencia básica entre la especie humana y otros animales?...El animal encerrado en la jaula de un parque zoológico manifiesta todas estas anormalidades que tan familiares nos son por nuestros compañeros humanos. Evidentemente, entonces, la ciudad no es una jungla de asfalto, es un zoo humano" ${ }^{30}$.

Este zoohumano es reflejado muy hábilmente por los creadores de los Simpsons, y nos hacen pensar sobre la decadencia de la naturaleza humana si es que alguna vez la hubo. Si alguien piensa que Los Simpsons son asquerosos, me imagina que no han visto Rem y Stimpy, eso sí es asqueroso. $Y$ resume el sentido autodestructivo de la morbosa sociedad (suciedad) capitalista.

\section{ESTO NO ES UNA COMIQUITA}

Hoy día en nuestra jerga venezolana la palabra comiquita, significa además de un dibujo animado algo que tiene que ver con alguien que se pone incómodo o como dicen los malandros 31 : "se pone Popi",32, es decir; se pone payaso. Por supuesto la comiquita en este sentido tiene que ver con lo que hace o dice este popi. Pero en relación con los Comics, los dibujos animados, las caricaturas, películas, y/o series de televisión que muestran estas características, (manifiesto en primer lugar que prácticamente no existen diferencias entre un género y otro). Me explico: si bien es cierto que casi todo esto comenzó con las historietas. Hoy día ya no es así, de hecho tenemos películas sobre comics, series televisivas de dibujos animados, y además series televisivas de

\footnotetext{
${ }^{30}$ Morris, Desmond. El zoohumano. Plaza y janes SA.., ediciones. España 1970.

${ }^{31}$ Los malandros son antisiciales y o excluidos sociales, que no sólo delinquen sino que además contribuyen la construcción de un lenguaje vivo que muta permanentemente y que hace de la lingüística un campo de estudio que no se asume como vigilantes y/o policía del lenguaje.

${ }^{32}$ La palabra Popi, nos recuerda también al fallecido actor y cantante Dioni López, quien por muchos años personifico en la televisión al Payaso Popi, Popi siempre trabajó para el canal más reaccionario y fascista de la televisión Venezolana. Radio Caracas televisión (RCTV). De allí que el ponerse popi sea algo más que una jerga malandra. Es en consecuencia todo un discurso ideológico.
} 
humanos que representan a los comics, y más allá aún seres humanos que sin saberlo son comics andantes reflejo de una cultura tremendamente ideologizada. Por supuesto alrededor de todo esto hallamos a toda una industria publicitaria que promueve a través de juguetes y ahora a través de video juegos la admiración y consecuente consumo relacionado con los comics. Es así la comiquita se ha transformado en toda una gran industria capitalista. Y la comiquita ha hecho de la vida cotidiana una gran comiquita.

Nuestros héroes han de ser seres no radiactivos ni super mutantes, han de ser seres especiales pero no tecnólogos hiperespecializados. Pero defensores del medio ambiente. Si han de ser por el contrario personas muy intuitivas que saben trabajar en equipo y que por ello promueven la organización comunal. De esos héroes tenemos por ejemplo: "chicas super poderosas", en cada una de las comunas en construcción de nuestro país, además tenemos muchos corre caminos que saben burlarse de los coyotes de la CIA y del pentágono. Tenemos además super-mujeres y super-hombres que sí saben ponerse bien los calzones y las pantaletas, y no como super man y batman, tenemos super héroes que son capaces de resistir guerras mediáticas y paros petroleros, y además super soldados que son capaces de luchar sin la super tecnología de la NASA. Por todo esto son y somos defensores de la consigna feminista que reza: "Arriba las faldas y abajo los pantalones", por ello nuestros héroes no son asexuados, al contrario les gusta mucho el sexo, o como diría un sexólogo, les gusta mucho la sexualidad. Nuestros héroes tampoco son ni hipertrofiados musculares, ni cyborgs ni robots. Son gente de carne y hueso, algunos de ellos son, más carne que hueso y viceversa, que sienten y viven un país y que además saben que contra ellos no hay guarimba, ni guerra mediática ni sabotaje petrolero ni mucho menos comiquita que valga. Otro asunto que vale la pena destacar es que en tiempos de depresión en los Estados Unidos, como lo es en este momento, los comics son los principales medios de propaganda en pro de las guerras que dicha nación lleva a través del mundo para vender sus armas y recuperarse económicamente a través de su cultura aniquiladora y egoísta.

Ahora observo comiquitas en todas partes, por ejemplo: esta mañana pasé por la sede de lo que antes era un comando policial, ahora es una escuela y liceo militarizado. ¿No es eso una comiquita. En el sentido Althusseriano y Focaultiano, creo que sí.

\section{LAS TELENOVELAS COMIQUITAS ¿O NO?}

La distinción entre comiquitas y/o no en relación a las telenovelas se hace un poco más compleja ya que la misma es un monstruo recursivo productor/reproductor de ideologías, tan es así que las personas que las ven/las hacen sienten que la lógica que se vislumbra en ellas. Las discusiones entre los semiólogos se dividen a favor y en contra de ellas. Yo particularmente no observo nada positivo en las mismas sin embargo caractericémoslas para luego proseguir el análisis: 
a) Todo gira en torno de una muchacha que por lo general es pobre y se enamora de un hombre rico. ${ }^{33}$

b) El hombre rico por lo general es infiel con casi todas las mujeres de la novela, sin embargo al final la muchacha lo perdona.

c) Por lo general hay un hombre o mujer malos que le hacen la vida imposible a la muchacha. ${ }^{34}$

d) Tanto el protagonista como la protagonista responden a los estereotipos de la belleza occidental. ${ }^{35}$

e) La ley de Muphy ${ }^{36}$, está presente en la vida de la protagonista hasta el final, cuando de cenicienta pasa a ser princesa.

f) Estas novelas además tienen gran carga de machismo, por ejemplo: nunca se sé el caso de un hombre pobre que se enamora de una mujer rica, él por lo general es quien la seduce, y si se casan él es quien trabaja y ella se queda en casa y si trabajan los dos, él gana más.

g) Lo demás es corolario, es decir; si es adoptada y al final descubre que también es rica, si en un momento ella o él se plantea una venganza contra él o la protagonista y luego lo perdona, etc., etc., etc.

En relación a esta caracterización puede haber elementos más, elementos menos pero en sentido genérico esa ha sido la fotografía de la telenovela latinoamericana, género que por cierto nació en nuestros territorios, en los países del norte no hacían llanto culebras como estas, creo que tal vez ahora si. La denigración del ser humano, la discriminación, la vida en torno al dinero, ${ }^{37}$ el no cuestionamiento de su realidad. La conformidad ante su lógica de vida, la pobreza en el lenguaje y la falta de argumentos. Hace de estos shows, toda una delicia para las mentes moribundas. Otra expresión de todo esto, es lo que ahora recibe el nombre de reality shows y es allí donde la realidad y la ficción se convierten en la misma porquería. Que razón tiene Eduardo Liendo ${ }^{38}$, casi le prendo una vela. Para cerrar en relación a la telenovela (que en realidad debería ser tele, no verla), las únicas variantes son: las locaciones, canciones, humor, escenas policiacas, y cualquier otra estupidez que se me haya olvidado. Con todo eso puedes fabricar una deliciosa merengada de nada.

\footnotetext{
${ }^{33}$ Por lo general la novela lleva el nombre de la muchacha.

${ }^{34}$ La variación hoy día es que el número de malos ha aumentado en la novela. Ahora son todos.

${ }^{35}$ Excepto en las novelas Brasileras, en las que los hombres poco agraciados hacen pareja con mujeres occidentalmente bellas.

${ }^{36}$ Edward Aloysius Murphy, (11 de enero de 1918 - 17 de julio de 1990 (72 años)) fue un ingeniero aeroespacial estadounidense. Murphy trabajó en sistemas de seguridad críticos y es conocido por la homónima Ley de Murphy, que declara que "Si hay varias maneras de hacer una tarea, y uno de estos caminos conduce al desastre, entonces alguien utilizará ese camino." Esto no debe ser confundido con la ley de Finagle.

http://es.wikipedia.org/wiki/Edward_A._Murphy_Jr.

${ }^{37}$ Cuanto tienes cuanto vales.

${ }^{38}$ Eduardo Liendo en su obra magistral, "El Mago de la Cara de Vidrio. No advierte de toda esta locura alienante que genera la televisión y en especial eso que llaman industria del entretenimiento. De hecho los vendedores de basura dicen que si hay entretenimiento no hay aprendizaje y viceversa.
} 
Más absurdo aún es cuando en una telecomiquita te citan a otra, por ejemplo: un personaje de la telenovela mejicana "el triunfo del amor dijo:

\section{"Todo chavo del ocho necesita su chilindrina".}

Difícilmente escucharemos a algún personaje decir cosas tales como:

- Disculpe Sra. Martínez pero las trabajadoras domesticas, nos hemos reunido y hemos conformado un sindicato. Nos oponemos a la explotación de la mujer por la mujer. o

Un obrero diciéndole al dueño de la empresa: Los trabajadores no sólo estamos interesados en obtener beneficios económicos, también queremos participar activamente en la producción y acabar con la plusvalía generando una mejor y mayor distribución de los recursos. De esta forma queremos ser copropietarios propiciando de este modo la propiedad colectiva de los medios de producción.

- $\quad$ O un niño diciéndole a su mamá:

¿Mami porque en la escuela nos enseñan tantas tonterías?, o ¿Qué es la dialéctica?

¿Es necesario pasar por la escuela para aprender a vivir?

Otra comiquita la vemos en y a través de uno de los políticos miembro de la oposición venezolana, a ver si lo identificamos en esta entrevista imaginaria:

\section{ENTREVISTA A HUEVO CHIMBO MONTIEL POR CHICHARRÓN PREGUNTÓN ${ }^{39}$}

En las relaciones políticas de nuestro país, surge un personaje al que nosotros denominamos el filósofo, aquí le entregamos una primicia, la entrevista que le realizara nuestro reportero estrella, esperamos que la disfruten:

Chicharrón (CHI): Saludos y respetos Sr. Huevo chimbo, en el País se preguntan mucho acerca de sus pretensiones presidenciales y se rumora que usted será el próximo presidente de la república, ¿Qué opina usted?:

Huevo chimbo (HU): No creo en cantos de ballena

(CHI): ¿Qué cree usted acerca del futuro del País?:

(HU): El futuro es mañana.

(CHI): ¿Qué opina usted acerca del hambre en el mundo?

(HU): - "Hay que atender las enfermedades infecciosas como la desnutrición"

(CHI): ¿Qué piensa usted de la delincuencia y de la Violencia en las calles?

(HU): "Voy a perfeccionar la inseguridad". "Sólo cuando la policía logre desorganizar al hampa, se podrá acabar con el crimen organizado".

(CHI): ¿Qué piensa usted de la educación?

(HU): "Los colegios están vueltos un desastre. Por ejemplo, en los salones de computación no hay microscopios ni reactivos para hacer experimentos".

(CHI): ¿Es posible cambiar toda esta situación que usted señala?

(HU): Tú quieres ir a pedir peras al horno

39 Texto tomado del trabajo de humor político de nombre: "Las aventuras de Cachapo, Sardina y Mortadela. Un salto cuántico en la vida del hombre y mujer criollo". Este trabajo también es autoría de Oscar Fernández y en estos momentos está en espera para ser publicado por la editorial el perro y la rana del ministerio de cultura. 
(CHI): ¿Está seguro de eso?

(HU): “Yo jamás afirmé que no hay que exigirle peras al horno. Lo que dije es que no hay que pedirle peras al horno".

$(\mathrm{CHI})$ : Creo que todo ha quedado claro, eso creo. Muchas gracias por la entrevista.

(HU): No hay por dónde.

Si Eduardo Liendo nos habla de un mundo de locos con la llegada del televisor, ¿qué diría de la televisión por cable, por satélite y/o por internet?

\section{LUDOVICO Y EL JUEGO}

Desconozco el origen del nombre "Ludovico", pero en esta nuestra Venezuela no faltaría uno de nuestros genios de la oposición que diría que Ludovico deriva de los juegos de azar y que Ludovico es en consecuencia un Ludópata de nacimiento. Sé que la idea suena super loca, pero un por ejemplo Rosales ${ }^{40}$ lo diría y luego se quedaría como si nada. Sin embargo sabemos que entre los juegos de mesa más populares aún se halla "el Monopolio", me imagino que si ese juego evoluciona se llamará oligopolio e incorporará alianzas estratégicas y actividades en la bolsa de valores. Tal vez puedan reproducir a nivel de juego lo que generó la actual crisis el sistema capitalista. Quizás entonces encontremos a niños micro y macro economistas con la solución que los adultos no hallaron. De repente salga algún bebé de 5 años diciendo que redistribuyendo todo los alimentos del mundo y permitiendo a los países pobres participar más abiertamente en el juego económico mundial se solucione todo. Al final entonces diríamos que todo fue un juego de niños que en lugar de competir entre ellos, cooperaron. Estoy seguro que de ese juego si participaría Ludovico. No me queda claro si Ludovico jugaría o no video juegos, sin embargo la ludopatía tras de estos es tremendamente adictiva, tanto que muchos niños y jóvenes dejan de ir a clases ${ }^{41}$ para perderse en estos experiencias virtuales. Para tratar de ser lo más justo posible, si es que la justicia no es otra trampa del sistema, (por supuesto que lo es), existen también video juegos que promueven ejercicios intelectuales, por ejemplo hay uno que se llama mystery P.I New York, en el cual se trabaja el desarrollo de la memoria de los participantes. Por supuesto no sin generar algunos mecanismos de alienación como el tener que recordar elementos tales como la bandera de estados Unidos y la estatua de la libertad. A parte de la trivialidad tras muchos de los objetos que presenta. Más sin embargo creo que la idea que gira en torno al hecho de recordar objetos, es muy útil para ayudar en problemas neurológicos a nivel de la memoria. Sólo habría que trabajar el tema de la ideología que busca vender cosas. Incluso se podría trabajar con estos materiales con jóvenes en cursos de formación político-contra ideológica, diciéndoles a los jóvenes que no sólo recuerden los objetos sino que además analicen y discutan la ideología oculta en los mismos.

${ }^{40}$ En las aventuras de Cachapo, Sardina y Mortadela huevo chimbo.

${ }^{41}$ Por otro lado entendiendo lo inoperante arcaico y alienante que representa el sistema educativo hoy día, tal vez sea preferible ver video juegos. 
Ya para finalizar queremos dejar una pequeña reflexión sobre el lenguaje y el como el recorcholis, zambomba, chanfle, caspita y caramba entre otros han sustituido a nuestro Toño el amable:

\section{"REFLEXIONES EN TORNO A TOÑO EL AMABLE"42}

Ca: En un envío anterior, les hablé acerca de las oscuridades y profundidades del término culo, que a deferencia de algunas creencias si termina en algún lugar del intestino delgado. Ahora bien démosle la vuelta al asunto, es decir hablemos ahora de otra parte del cuerpo que no deja de ser oscuro también pero que su ubicación la tenemos, (o mejor dicho le tienen) en el lado opuesto al culo, (claro en el caso de las mujeres y los transformistas). Me refiero a la vagina, o también llamada totona, cosita, chacarita, bichita, fufufa, etc. No faltará quien le coloque un nombre propio como Petra, María o Josefina, el hecho está en que todos estos nombres se vuelven genéricos cuando aparece, la popular palabra: "Coño", si no lo sabían el término coño se refiere a la fulana señora descrita arriba (llámese vagina), de allí expresiones tales como:

\section{"Coño é tu madre", "Coño é su madre", y Coño é la madre" "Coño é madre"}

Las cuatro aunque a veces son usadas de forma indiscriminada, pueden tener usos específicos, por ejemplo: si nos referimos a una persona que va en la carretera y otra lo rebasa de forma un tanto imprudente, este le gritaría: "Coño é tu madre", y allí no influye el hecho de si conoce o no a la progenitora de dicho sujeto (masculino o femenino). Si se trata de algo que tenía que ver contigo y se le olvido a alguien, le diríamos: "Coño é su madre", si se trata por el contrario de algo que se nos olvidó a nosotros mismos, diríamos: "Coño é la madre", y por último si nos referimos a alguien ya sea con rabia o con cariño decimos ese es un: "Como é madre".

En fin este término tiene mucha tela que cortar sobre todo desde la idiosincrasia del venezolano. 0 ¿prefieren un recorcholis o un repámpanos en lugar de un buen COÑO?

\section{¿Pero que coño vamos a hacer con todo esto?}

Tal vez nada, ¿pero no es sabroso, conocer en profundidad lo infinitamente borroso que son nuestros códigos?, pues gracias a esto nos hemos salvado de la dominación, y todo gracias a la vagina, que hace de la mujer un ser infinitamente plural y especial. $Y$ no es que pensemos en la mujer como una vagina con cuerpo. No, eso nunca. Pero por extrapolación sacamos, que si las vaginas son múltiples, también lo son ellas. Eso no lo tomen como una ley, pero queda allí para el debate, en fin si esto no les gusta, no sigan leyendo un coño. Y váyanse todos para el coño é... Por otro lado si cotejamos todo esto con el tema que nos ocupa, es decir; los comics y en consecuencia las comiquitas ideológicas que de alguna u otra forma consumimos y generamos

\footnotetext{
${ }^{42}$ Tomado de las aventuras de Cachapo, Sardina y Mortadela un salto cuántico en la vida del hombre y mujer criollos. Esta reflexión la hace Cachapo.
} 
en nuestra cotidianidad, el término coño se queda pequeño ante lo tremendamente pasivos que hemos sido a pesar de la vaguedad de nuestro lenguaje que si bien nos ha salvado por un lado, por el otro nos ha separado de nuestro horizonte recursivo signito/interpretativo dialéctico. (¿Que coño dije?). En realidad no lo sé pero suena a lenguaje intelectual. Allí les dejo esa, para que hagan lo que puedan con sus vidas.

\section{SOSPECHANDO DE LA SOSPECHA}

Si todo es sospechoso de ser ideología desde la perspectiva Marxista, entonces la contra ideología, la contra cultura y el y/o los marxismos no escapan de esta sospecha. Es sospechosa la contra ideología que pronto se vuelve instrumento publicitario como Green peace o el prefijo bio y el prefijo eco en los productos de consumo masivo. Es sospechoso el marxismo que se hace dogma y cual religión impone caminos indiscutibles a seguir. Es sospechosa la promesa política venga de donde venga. Es sospechoso el populismo en el gobierno de la república bolivariana de Venezuela. Es sospechoso llamar contra revolucionario y/o quinta columna a quien observa fallas en el proceso revolucionario en construcción. Es sospechoso seguir a algún líder, sea quien sea como quien sigue a un Dios. Es sospechoso el antiburocratismo que se hace más burocrático incluso con una ley antiburocratismo. Es sospechosa la ciencia y la tecnología que no se autocuestiona. Es sospechosa la educación que no se autodestruye. Es sospechoso el dirigente político que no piensa ni le interesa el pensar. Es sospechoso el libro que no se lee y también lo es el que se le demasiado. Es sospechoso el hambre y la miseria. Es sospechosa la boliburguesia. La lista podría ser interminable sin embargo lo que queremos destacar aquí es que no podemos limitar el análisis. En una ocasión le preguntaron a un matemático sobre la existencia de Dios, y el respondió diciendo que: si Dios creo todo lo que existe, ¿Quién creó a Dios? Y ¿Quién creó a al que creó a Dios? Y así sucesivamente hasta el infinito. En ese sentido podríamos decir que el pensamiento en torno a mundo mejor y/o a una sociedad equilibrada no se detiene en las ideas que en este momento podamos tener en relación a la misma la cual por ahora denominamos socialismo y/o comunismo sino que ese análisis nunca termina. $Y$ no queremos/quiero quedarnos/quedarme en un enfoque seudo-relativista que asume que todo es relativo, porque entonces tendríamos que preguntarnos cual Heinsemberg en el libro $A B C$ de la relatividad: "Si todo es relativo, ¿que sería relativo a ese todo?", sólo debo y/o quiero puntualizar que hasta la lógica que usualmente aplicamos en nuestro lenguaje, es y puede ser una trampa ideológica de la cual a pesar de la crítica y la autocrítica dialéctica o no al ir de nuevo a las letras y a las palabras retornamos a la trampa de la cual creímos haber escapado. Sobre el mismo Marx, se rumora que en una ocasión llegó a decir; que él mismo no se asumía marxista. Queriendo significar con esto que él no se hacía responsable de las interpretaciones buenas y/o malas derivadas de su pensamiento. También se dice que en alguna ocasión llegó a decir; que la religión es el opio de los pueblos. Del mismo modo se rumora que Federico Nietzsche llegó a decir; que el marxismo era la religión de los oprimidos. Hasta ahora estas expresiones no han podido ser halladas en ningún texto a modo de referencia por ello las 
señalo como rumores. Sin embargo más allá de si lo dijo o no lo dijo, quiero significar el impacto que pudo o no haber ejercido un determinado pensamiento más allá de su autor. Esto es importante que sea analizado porque desde esta perspectiva incluso la autoría y su sacrosanta relación con los lectores queda también bajo sospecha. Sobre todo después que Ludwig Wittgenstein dijo que la originalidad no existe. Otro elemento que podríamos incluir dentro del laberinto de las sospechas es el caso de la contra ideología vuelta ideología. Un caso ejemplar de lo antes dicho, es la imagen del Che Guevara que se ha popularizado y comercializado a tal punto que ha llegado a ser comparada con la imagen de Cristo generando de este modo un culto a la imagen y toda una ola de comercialización que se aleja mucho del ideal socialista. De este fenómeno no quedamos exentos aquí en la revolución bolivariana donde no sólo vemos a personas usando franelas, gorras y demás productos con imágenes de iconos de la revolución, sino que además vemos aberraciones semióticas tales como una franela con la imagen del Che con una gorra del FBI. Y más allá de eso observamos en nuestros compatriotas que poseen una gran confusión de ideas políticas, las cuales lamentablemente se hallan profundamente entronizadas en la dirigencia de la revolución. Desde esta perspectiva la revolución bolivariana, su dirigencia y el PSUV caen también bajo sospecha de ser ideología.

\section{REFERENCIAS COMPLEMENTARIAS}

Asimov, Isaac. Civilizaciones extraterrestres. Editorial Bruguera. España 1981.

-- Yo Robot. Colección Nebular № 1, Edhasa. Barcelona España. 1975.

Adame Cerón, Miguel Ángel. Redes urbanas y virtuales del capitalismo "glocal" Rebelión.org.

Baudrillard, Jean (1993). Cultura y simulacro, Barcelona, Ed. Kairós.

Gil de San Vicente, Iñaki. La dialéctica como arma, método, concepción y arte. www.lahaine.org

DORFMAN, Ariel y MATTELART, Armand (1972) Para leer al Pato Donald. Siglo XXI, Buenos Aires.

Gutiérrez López, María Asunción. Sobre la complejidad e influencia del pensamiento de Karl Marx. Revista de Filosofía. A Parte Rei 25.

Himanen, Pekka. La ética del hacker y el espíritu de la era de la información. http://www.educacionenvalores.org/IMG/pdf/pekka.pdf.

Kohan, Néstor. Nuestro Marx. Boedo, septiembre de 2009.

Mora Rubio, Juan. Lo que Marx dijo de la Dialéctica.

Liendo Eduardo (1973). El mago de la cara de vidrio. Novela. Monte Ávila Editores

Schmucler, Héctor (1972) "Donald y la política", en A. Dorfman y A. Mattelart, Para leer al Pato Donald, pp. 3-8. 